\title{
Laryngeal polyp associated with reflux disease: a case report
}

Wael Abdo Hassan ${ }^{1,2}$ (D)

\begin{abstract}
Background: Among the most common benign laryngeal lesions are vocal nodules and polyps. Their etiology is related to vocal abuse. Gastroesophageal reflux disease is a common condition presenting with a broad spectrum of symptoms, among which are extraesophageal manifestations such as laryngeal polyps.

Case presentation: A 24-year-old Middle Eastern woman presented to the author's institution with dysphonia and dyspepsia. She underwent endoscopy and was diagnosed with severe reflux disease. In addition, laryngoscopy revealed a polyp at the left vocal cord, and the patient underwent polypectomy. Histopathological examination revealed a laryngeal polyp of telangiectatic type characterized by hyperplastic epithelial covering with reactive atypia, prominent superficial acanthosis with neutrophils, and prominent chronic inflammation and thrombosed vessels in the stroma.
\end{abstract}

Conclusion: This report focuses on the pathological findings associated with a laryngeal polyp in a young patient diagnosed with severe reflux disease. Acknowledging such characteristic changes in a laryngeal polyp could aid in the diagnosis of gastroesophageal reflux disease.

Keywords: Laryngeal polyp, Gastroesophageal reflux disease, Pathological changes

\section{Background}

Laryngeal polyp is defined pathologically as a noninflammatory response to laryngeal injury usually caused by vocal cord abuse and irritation [1]. "Vocal abuse" refers to misuse of vocal behaviors leading eventually to trauma of the laryngeal mucosa, such as by excessive talking, prolonged and excessive loudness, and the use of inappropriate pitch [2]. Thus, it is more common in singers [1]. The most common clinical manifestation is voice change: generalized and persistent hoarseness, change in voice quality, and increased effort in producing the voice [3]. The usual location of polyps on the superior surface of the cord makes it easy to visualize them by video stroboscopic examination [3]. There are several other causes of laryngeal polyps, despite being less common, such as gastroesophageal reflux disease (GERD), and chronic inhalation of irritants (such as industrial fumes and cigarette smoke). GERD symptoms

\section{Correspondence: w.hassan@sr.edu.sa}

1 Department of Pathology, Faculty of Medicine, Suez Canal University, Ismailia, Egypt

2Department of Basic Sciences, Sulaiman Al Rajhi Colleges, PO Box 777, Al Bukayriyah 51941, Kingdom of Saudi Arabia are described as typical if they present with digestive symptoms (e.g., pyrosis, regurgitation, back breastbone pain) and atypical if the symptoms are extraesophageal, related to the larynx, the pharynx, or other respiratory airways (e.g., cough, dysphonia, dysphagia) [4, 5]. The causes of GERD are multifactorial and include many well-described factors [6], all of which are associated with transient lower esophageal sphincter relaxation that allows a bolus of refluxate to move from the stomach into the esophagus [6]. One of the defense mechanisms in combating gastric reflux is the upper esophageal sphincter (cricopharyngeus), whose pressure might fail to increase in response to esophageal acid exposure, leading to laryngopharyngeal reflux (LPR) [7]. The exact etiology behind the failure of the upper sphincter is uncertain; however, it is also clear that such failure is reversible with effective antireflux treatment [7]. LPR has been associated with vocal cord polyps, vocal cord granulomas, laryngospasm, laryngeal carcinoma, and subglottic stenosis [8]. We report a case of vocal cord polyp diagnosed in a patient with severe GERD.

(c) The Author(s). 2019 Open Access This article is distributed under the terms of the Creative Commons Attribution 4.0 International License (http://creativecommons.org/licenses/by/4.0/), which permits unrestricted use, distribution, and reproduction in any medium, provided you give appropriate credit to the original author(s) and the source, provide a link to the Creative Commons license, and indicate if changes were made. The Creative Commons Public Domain Dedication waiver (http://creativecommons.org/publicdomain/zero/1.0/) applies to the data made available in this article, unless otherwise stated. 


\section{Case presentation}

A 24-year-old Middle Eastern woman presented to the author's ear, nose, and throat (ENT) clinic with a complaint of dysphonia that had been present for 2 months. The patient gave no history of any intubations, trauma, or voice abuse. She had associated dyspeptic symptoms. On examination of the ear, nose, and throat, a polypoid lesion was present on the middle one-third region of the left vocal cord measuring approximately $4 \times 3 \mathrm{~cm}$ in diameter. The patient was referred to the gastroenterology clinic to undergo endoscopy. She was diagnosed with grade $C$ GERD on the basis of the Los Angeles classification system of GERD. Returning to the ENT clinic, the patient was scheduled for surgery for removal of the laryngeal polyp. With the patient under general anesthesia, the polypoid lesion was excised completely by suspension direct laryngoscopy, with no residual tissue left behind.

The excised polyp was fixed in 10\% formalin and embedded in paraffin. Serial sections, $5 \mu \mathrm{m}$ thick, were processed for hematoxylin and eosin (H\&E) staining. Immunohistochemistry (IHC) staining was carried out with the streptavidin-biotin method. Primary antibodies (Additional file 1: Table S1) were purchased from Genemed Biotechnologies (San Francisco, CA, USA).
On gross pathological examination, the specimen consisted of a polypoid mass measuring $4 \times 3 \mathrm{~cm}$ with a smooth outer surface and a congested cut section. Histologically, as observed by H\&E) staining, the polyp was lined with thickened, nonkeratinized, stratified, squamous epithelial covering with disruption of superficial layers of epithelium causing small blisters with intraepidermal microabscesses and underlying areas of hemorrhage (Fig. 1a). The basal epithelial cells were thickened with elongation of rete ridges and mild atypical changes involving the lower third of the epithelial covering in the form of enlarged hyperchromatic nuclei and mild disturbed polarity (Fig. 1b). The underlying stroma showed numerous proliferated blood vessels (Fig. 1c), with some of them dilated with congestion and others with thrombi. Nests of uniform stratified squamous epithelium were present within the stroma and surrounded with basement membrane, representing pseudoepitheliomatous hyperplasia. Dense fibrous tissue deposition was present in the stroma, with focal areas of edema and chronic inflammatory cell infiltrate and numerous focal accumulations of clear cells with enlarged nuclei. Focal separation of overlying epithelial covering by edema was seen (Fig. 1d). Focal ulceration with underlying granulation tissue-like reaction was also observed.

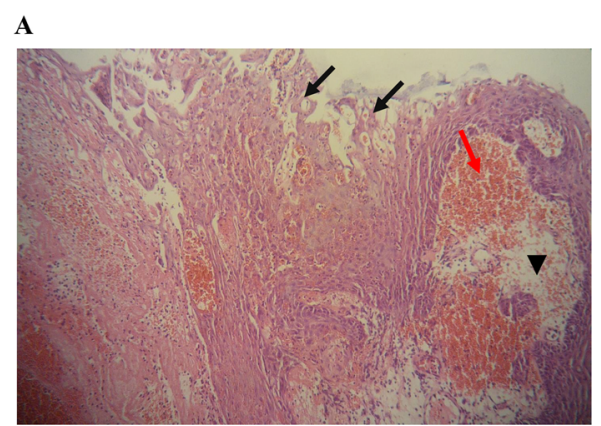

B

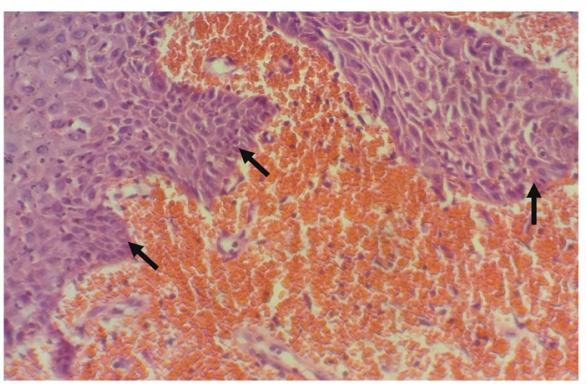

C

D
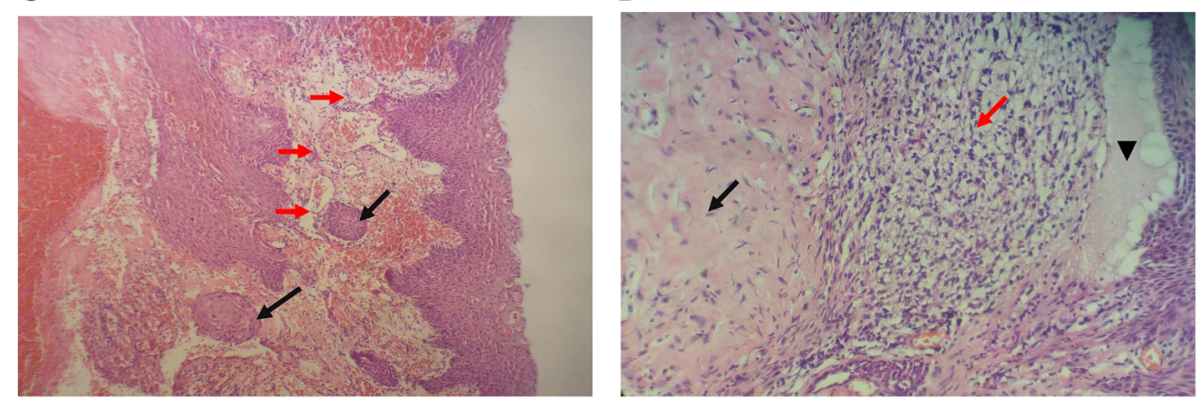

Fig. 1 Histopathological features of laryngeal polyp. a The polyp is lined with thickened, nonkeratinized, stratified squamous epithelial covering with disruption of superficial layers of epithelium causing intraepidermal microabscesses (black arrows). The underlying stroma shows edema (arrowhead) and hemorrhage (red arrow) (Hematoxylin and eosin stain (H\&E) stain, original magnification $\times 100$ ). b Focal elongation of rete ridges is present with mild atypical epithelial cell changes (black arrows) (Hematoxylin and eosin stain (H\&E) stain, original magnification $\times 200$ ). $\mathbf{c}$ The underlying stroma shows numerous proliferated blood vessels (red arrows); some are congested. Two nests of uniform squamous epithelium are present with intracellular keratinization and surrounded with basement membrane, representing uniform foci of pseudoepitheliomatous hyperplasia (black arrows) (Hematoxylin and eosin stain (H\&E) stain, original magnification $\times 40$ ). $\mathbf{d}$ The stroma shows dense fibrous tissue deposition (black arrow) with numerous focal accumulations of foamy macrophages (red arrow). Focal separation of the overlying epithelial covering with edema is present (arrowhead) (Hematoxylin and eosin stain (H\&E) stain, original magnification $\times 200$ ) 
Table 1 Summary for laryngoscopic and pathological features for laryngeal nodule and polyps

\begin{tabular}{|c|c|c|}
\hline & Vocal cord nodule & Vocal cord polyp \\
\hline $\begin{array}{l}\text { Laryngoscopic } \\
\text { findings }\end{array}$ & $\begin{array}{l}\text { Sessile, gray white, usually bilateral, in the } \\
\text { anterior or middle third of the vocal folds }\end{array}$ & $\begin{array}{l}\text { Pedicled, gray white/red, usually unilateral, located in the anterior and middle } \\
\text { thirds of the vocal folds }\end{array}$ \\
\hline Size & Usually less than $0.3 \mathrm{~cm}$ & Usually greater than $0.3 \mathrm{~cm}$ \\
\hline $\begin{array}{l}\text { Pathological } \\
\text { features }\end{array}$ & $\begin{array}{l}\text { Parakeratotic, stratified, squamous epithelial } \\
\text { covering overlying dense fibrotic stroma } \\
\text { There is prominent basement membrane } \\
\text { thickening. } \\
\text { Hemorrhage or hemosiderin-laden macro- } \\
\text { phages are not usually seen. }\end{array}$ & $\begin{array}{l}\text { Two types: } \\
\text { 1. Telangiectatic polyps: orthokeratotic, stratified, squamous epithelial covering } \\
\text { overlying numerous thin-walled, dilated vessels in edematous stroma; areas of } \\
\text { hemorrhage and hemosiderin-laden macrophages are usually seen } \\
\text { 2. Gelatinous polyps: stratified, squamous epithelial covering overlying edematous } \\
\text { stroma containing fibrin, proliferating fibroblasts, and few thin-walled vessels }\end{array}$ \\
\hline
\end{tabular}

By IHC staining, a negative reaction to p53 in the overlying epithelium was detected, thus excluding the possibility of epithelial dysplasia. In addition, E-cadherin expression was decreased in the superficial layers of the squamous epithelial covering, leading to intercellular spongiosis and the accumulation of neutrophils with microabscess formation. The accumulated clear cells stained positive for CD68 and negative for pan-cytokeratin, confirming their nature as foamy macrophages.

\section{Discussion and conclusions}

Vocal cord polyps and nodules are among the most common prevalent laryngeal lesions (1.0-1.7\%), with a slight female and pediatric predominance [9]. They are typically caused by vocal overuse, whereas other irritants may contribute to the development of polyps, such as GERD, smoking, and aspiration of chemical substances [9]. Differentiation between vocal cord nodules and polyps can be done on the basis of both laryngoscopic and pathological parameters [10]. From a histological point of view, vocal cord polyps are classified as telangiectatic and gelatinous polyps. Table 1 summarizes the laryngoscopic and pathological features of vocal cord nodules and polyps $[10,11]$. On the basis of these data, the present case represents a vocal cord telangiectatic polyp. GERD has been implicated in the pathogenesis of vocal cord nodules and polyps, possibly due to adductory collision of the vocal cord by the effect of reflux, which results in local trauma, inflammation, and irritation [12]. Moreover, higher presence of pepsin was reported in patients with vocal cord polyps than in a control group [9]. Other laryngeal complications of GERD include paradoxical vocal fold motion, laryngospasm, laryngeal granuloma, stenosis, strictures, ulcers, chronic laryngitis, and laryngeal carcinoma [6, 13-16]. It has been estimated that $55-79 \%$ of patients who present with unresponsive hoarseness resulting from chronic laryngitis have acid reflux [14].

The present patient had the clinical and pathological features of a vocal cord polyp associated with GERD. The clinical features included dysphonia associated with dyspepsia. The pathological features included epithelial changes; thickening of the epithelial lining with microabscesses, reactive atypia, pseudoepitheliomatous hyperplasia, and stromal changes; vascular proliferation; hemorrhage; thrombosis edema; fibrous deposition and increased number of foamy macrophages. Despite the presence of atypical epithelial cell changes, a negative reaction to p53 excluded the possibility of dysplasia $[17,18]$. On the one hand, acknowledging such a spectrum of changes in a laryngeal polyp could aid in the diagnosis of associated GERD. On the other hand, smoking-associated vocal cord polyps are characterized by significant epithelial hyperplasia, leukoplakia, thickened basement membrane, hyaline degeneration, and lamina propria edema $[9,11]$.

The preferred treatment in all patients with larynxassociated GERD features is aggressive antireflux therapy combined with speech therapy [14]. Marked improvement could be achieved in the associated laryngeal lesions, such as granulomas and subglottic stenosis, with antireflux therapy alone [15]. Patients with laryngeal polyps, as in the present patient, require surgical intervention for removal of the polyp to avoid airway obstruction and should be given aggressive antireflux therapy preoperatively and maintained on it postoperatively [13].

Regarding the present patient, following laryngeal polypectomy, she was treated with both a proton pump inhibitor ( $1 \mathrm{mg} / \mathrm{kg}$ body mass) and histamine $\mathrm{H} 2$ receptor antagonists ( $1 \mathrm{mg} / \mathrm{kg}$ body mass) for 6 months in addition to erythromycin (500 mg twice daily) for 5 days, and an antireflux diet was prescribed by the gastroenterologist. After treatment, the patient was assessed, and she showed dramatic improvement. The patient remains under constant follow-up in a gastrological and laryngological outpatient clinic.

\section{Supplementary information}

Supplementary information accompanies this paper at https://doi.org/10. 1186/s13256-019-2324-0.

Additional file 1: Table S1. Antibodies for immunohistochemistry. Lot and working dilutions of antibodies are indicated.

\section{Acknowledgements}

The author extends special thanks to M. Saad for his technical skills in preparing histopathological slides. 


\section{Authors' contributions}

The corresponding author diagnosed the case pathologically and prepared the manuscript. The author read and approved the final manuscript.

\section{Funding}

All pathological studies in this report were funded by the author.

\section{Availability of data and materials}

Data sharing is not applicable to this article, as no datasets were generated or analyzed during the current study.

\section{Ethics approval and consent to participate}

This study was approved by the committee of ethics in the Faculty of Medicine, Suez Canal University, Egypt (no. 12457).

\section{Consent for publication}

Written informed consent was obtained from the patient for publication of this case report and any accompanying images. A copy of the written consent is available for review by the Editor-in-Chief of this journal.

\section{Competing interests}

The author declares that he has no competing interests.

Received: 26 August 2019 Accepted: 21 November 2019

Published online: 04 January 2020

\section{References}

1. Wallis L, Jackson-Menaldi C, Holland W, Giraldo A. Vocal fold nodule vs. vocal fold polyp: answer from surgical pathologist and voice pathologist point of view. J Voice. 2004;18(1):125-9.

2. Cipriani NA, Martin DE, Corey JP, et al. The clinicopathologic spectrum of benign mass lesions of the vocal fold due to vocal abuse. Int I Surg Pathol. 2011;19(5):583-7.

3. Cho KJ, Nam IC, Hwang YS, et al. Analysis of factors influencing voice quality and therapeutic approaches in vocal polyp patients. Eur Arch Otorhinolaryngol. 2011;268(9):1321-7.

4. Hom C, Vaezi MF. Extra-esophageal manifestations of gastroesophageal reflux disease: diagnosis and treatment. Drugs. 2013;73(12):1281-95.

5. Mosca F, Rossillo V, Leone CA. Manifestations of gastro-pharyngo-laryngeal reflux disease. Acta Otorhinolaryngol Ital. 2006;26(5):247-51.

6. Koufman JA. The otolaryngologic manifestations of gastroesophageal reflux disease (GERD): a clinical investigation of 225 patients using ambulatory 24hour $\mathrm{pH}$ monitoring and an experimental investigation of the role of acid and pepsin in the development of laryngeal injury. Laryngoscope. 1991: 101(4 pt 2 Suppl 53):1-78.

7. Koufman JA. Perspective on laryngopharyngeal reflux: from silence to omnipresence. classics in voice and laryngology. In: Branski R, Sulica L, editors. Classics in voice and laryngology. San Diego: Plural Publishing; 2009. p. 179-266.

8. Koufman JA. Low-acid diet for recalcitrant laryngopharyngeal reflux: therapeutic benefits and their implications. Ann Otol Rhinol Laryngol. 2011; 120(5):281-7.

9. Vasconcelos D, Gomes A, Araújo C. Vocal fold polyps: literature review. Int Arch Otorhinolaryngol. 2019;23(1):116-24.

10. Bohlender J. Diagnostic and therapeutic pitfalls in benign vocal fold diseases. GMS Curr Top Otorhinolaryngol Head Neck Surg. 2013;12:Doc01. https://doi.org/10.3205/cto000093.

11. Nunes RB, Behlau M, Nunes MB, Paulino JG. Clinical diagnosis and histological analysis of vocal nodules and polyps. Braz J Otorhinolaryngol. 2013;79(4):434-40. https://doi.org/10.5935/1808-8694.2013007.

12. Kuhn J, Toohill RJ, Ulualp SO, et al. Pharyngeal acid reflux events in patients with vocal cord nodules. Laryngoscope. 1998;108(8 Pt 1):1146-9.

13. Postma GN, Halum SL. Laryngeal and pharyngeal complications of gastroesophageal reflux disease. Gl Motil Online. 2006; https://doi.org/10. 1038/gimo46.

14. Vaezi MF, Hicks DM, Abelson TI, Richter JE. Laryngeal signs and symptoms and gastroesophageal reflux disease (GERD): a critical assessment of cause and effect association. Clin Gastroenterol Hepatol. 2003;1 (5):333-44.

15. Koufman JA, Amin MR, Panetti M. Prevalence of reflux in 113 consecutive patients with laryngeal and voice disorders. Otolaryngol Head Neck Surg. 2000;123(4):385-8.
16. Little FB, Koufman JA, Kohut RI, Marshall RB. Effect of gastric acid on the pathogenesis of subglottic stenosis. Ann Otol Rhinol Laryngol. 1985; 94:516-9.

17. Gusterson BA, Anbazhagan R, Warren W, et al. Expression of p53 in premalignant and malignant squamous epithelium. Oncogene. 1991;6(10): $1785-9$.

18. Mondal D, Saha K, Datta C, et al. Ki67, p27 and p53 expression in squamous epithelial lesions of larynx. Indian J Otolaryngol Head Neck Surg. 2013;65(2):126-33.

\section{Publisher's Note}

Springer Nature remains neutral with regard to jurisdictional claims in published maps and institutional affiliations.
Ready to submit your research? Choose BMC and benefit from:

- fast, convenient online submission

- thorough peer review by experienced researchers in your field

- rapid publication on acceptance

- support for research data, including large and complex data types

- gold Open Access which fosters wider collaboration and increased citations

- maximum visibility for your research: over $100 \mathrm{M}$ website views per year

At $\mathrm{BMC}$, research is always in progress.

Learn more biomedcentral.com/submissions 